\title{
Geodemographic insights on the COVID-19 pandemic in the State of Wisconsin and the role of risky facilities
}

\author{
Tony H. Grubesic (id) Jake R. Nelson • Danielle Wallace • John Eason • \\ Sherry Towers $\cdot$ Jason Walker
}

Accepted: 20 August 2021 / Published online: 12 September 2021

(C) The Author(s), under exclusive licence to Springer Nature B.V. 2021

\begin{abstract}
The COVID-19 pandemic caused by the severe acute respiratory syndrome coronavirus 2 (SARS-CoV-2) continues to impact the United States. While age and comorbid health conditions remain primary concerns in the community-based transmission of the virus, empirical evidence continues to suggest that substantial variability exists in the geographic and geodemographic distribution of COVID19 infection rates. The purpose of this paper is to provide an alternative, spatiotemporal perspective on the pandemic using the state of Wisconsin as a case study. Specifically, in this paper, we explore the geographic nuances of COVID-19 and its spread in Wisconsin using a suite of spatial statistical approaches. We link detected hot spots of COVID19 to local geodemographic profiles and the presence of high-risk facilities, including federal and state correctional facilities. The results suggest that the virus disproportionately impacts several communities
\end{abstract}

T. H. Grubesic $(\bowtie) \cdot$ J. R. Nelson

Geoinformatics and Policy Analytics Laboratory, School of Information, University of Texas at Austin, 1616

Guadalupe St., Austin, TX 78701, USA

e-mail: grubesic@utexas.edu

J. R. Nelson

Department of Geosciences, Auburn University, Auburn,

USA

D. Wallace

Center for Violence Prevention and Community

Solutions, Arizona State University, Tempe, USA and geodemographic groups and that proximity to risky facilities correlates to increased community infection rates.

Keywords COVID-19 - Geography $\cdot$ Spatial analysis $\cdot$ Prisons $\cdot$ Geodemographics

\section{Introduction}

The virus responsible for the COVID-19 pandemic is the severe acute respiratory syndrome coronavirus 2 (SARS-CoV-2). As detailed by Velavan and Meyer (2020), SARS-CoV-2 likely transitioned from animals to humans in/around the Huanan seafood market in Wuhan, China, although this remains an open empirical question (Jin et al., 2020). The main transmission

\author{
J. Eason \\ Department of Sociology, University of Wisconsin \\ Madison, Madison, USA \\ S. Towers \\ Institute for Advanced Sustainability Studies, Potsdam, \\ Germany \\ J. Walker \\ School of Criminology and Criminal Justice, Arizona \\ State University, Tempe, USA
}


routes for COVID-19 are respiratory droplets and contact transmission (Meselson, 2020). While all races and ages are susceptible to the virus, elderly persons (Velavan \& Meyer, 2020) with underlying comorbidities such as diabetes, asthma, and cardiovascular disease are particularly at-risk (B. Wang et al., 2020). Research also suggests that smoking and obesity may increase susceptibility (Dietz \& Santos-Burgoa, 2020; Patanavanich \& Glantz, 2020).

While research on the virology, mechanics of transmission, and vaccines for COVID-19 continues, it is essential to acknowledge that information concerning the pandemic's epidemiological facets are only beginning to emerge. For example, it is widely recognized that without pharmaceutical intervention strategies, social distancing was one of the few viable tactics to control the spread of COVID-19 (Lewnard \& Lo, 2020). The basic idea for social distancing is a simple one-reduce the mixing of infectious and susceptible people. When combined with contact tracing, masking, and aggressive testing for the virus, it should have been possible to "flatten" the epidemic curve in the United States and elsewhere (Chiu et al., 2020). Alas, this did not happen. Using data from Mar 12-Dec 23, Camberg et al. (2020) reported that December 2020 was the deadliest month of the pandemic to date, with an average of 2506 deaths reported per day and more than 119,000 people hospitalized with COVID-19. ${ }^{1}$

While these figures are alarming by themselves, empirical work increasingly suggests that COVID-19 infections disproportionately impact racial minorities, especially those that are impoverished. For example, in a cross-sectional study of $\sim 2500$ adults in Milwaukee, Wisconsin, COVID-19 was positively associated with African Americans, with both race and poverty associated with a higher risk of hospitalization (Muñoz-Price et al., 2020). In related work, Holtgrave et al. (2020) found that fatality rates for Black nonHispanic and Hispanic adults with COVID-19 were 3.48 and 5.38 times higher when compared to white adults suffering from the virus in the state of New York. In addition, Strully et al. (2021) identified significant regional variations in COVID-19 cases. Specifically, communities with more immigrants and

\footnotetext{
${ }^{1}$ Media reports from January 2021 indicate that it surpassed December 2020 as the deadliest month, with 95,000 U.S. residents dying from COVID-19 (Moser, 2021).
}

Central American or Black Residents exhibited more COVID-19 cases. Simultaneously, counties in the Northeast and Midwest that had more Puerto Rican residents also produced more cases.

While this research helps identify important differences in hospitalization and mortality rates between demographic groups, it says little about potential variations in lifestyle characteristics between groups, the spatial distribution of these groups, or the potential role that risky facilities may play in elevating risk and community exposure to COVID-19. The purpose of this paper is to provide an alternative, spatiotemporal perspective on the pandemic using the state of Wisconsin as a case study. Specifically, this paper explores the geographic nuances of COVID-19 and its spread in Wisconsin using a suite of spatial statistical approaches. The analysis detects and links hot spots of COVID-19 to local geodemographic profiles, their associated lifestyle characteristics and spatial distributions, as well as the presence of high-risk facilities, including federal and state correctional facilities. The results suggest that the virus disproportionately impacts several communities and geodemographic groups and that proximity to risky facilities correlates to increased community infection rates.

This work is important for several reasons. First, the epidemiological interactions between correctional facilities and their surrounding communities, broadly defined, remain poorly understood (Wang et al., 2020; Widra \& Herring, 2020). The empirical work presented in this paper deepens our understanding of these interactions using the spread of COVID-19 in Wisconsin as a case study. Second, an ability to pinpoint vulnerable communities and risky facilities within a study region is critical for public health intervention efforts. Although spatiotemporal dynamics of COVID-19 and viruses like it are relatively well understood (e.g., concentrations of a population with increased mobility amplify the spread), there will be other viruses or bacterial agents in the future that may not have such obvious transmission pathways (Witte et al., 2020; Zhu et al., 2018). The empirical framework that we highlight in this paper is generalizable and easily reconfigured to examine alternative pathogens, diseases, or transmission vectors. Lastly, the use of geodemographic measures is novel. Lifestyle habits and characteristics play an essential role in public health, especially when it comes to public health messaging, community support, and intervention 
strategies (Grubesic \& Durbin, 2020; Grubesic et al., 2014; Moon et al., 2019; Petersen et al., 2011) and it is crucial to account for their nuances when exploring issues of community health. More importantly, identifying vulnerable geodemographic groups and their spatial distribution is critical for increasing the efficiency of intervention efforts. For example, suppose certain groups prove to be more vulnerable because of their spatial distribution relative to risky facilities. In that case, the ability to prospectively identify these geodemographic groups in other locations (e.g., outside of Wisconsin) may help prioritize local public health efforts in these communities.

\section{Background}

As detailed in the introduction, the COVID-19 pandemic is fueled by a complex constellation of demographic (Dowd et al., 2020; Nepomuceno et al., 2020), geographic (Hohl et al., 2020; Smith \& Mennis, 2020), economic (Baker et al., 2020; Chetty et al., 2020), psychological (Babore et al., 2020; Thakur \& Jain, 2020), sociological (Bavel et al., 2020), political (Barberia \& Gómez, 2020; Bosancianu et al., 2020) and cultural factors (Huynh, 2020).

A complementary approach to deepening our understanding of COVID-19 is to evaluate its impacts within the framework of vulnerability. Broadly defined, vulnerable groups of people are those that are disproportionately at risk for stressors and shocks, whether social (Cutter et al., 2003), physical (Brody et al., 2008), economic (Briguglio et al., 2009), or cultural (Nazroo, 1998). The underlying challenge for evaluating the impacts of COVID-19 within this framework is that the inclusion of people in these groups can change rapidly. The Lancet $(2020,4)$ notes that vulnerable groups during the COVID-19 pandemic are not limited to the elderly or those with comorbidities. It includes those that might be under-housed or homeless and people from a large gradient of socio-economic groups. All of these groups can struggle mentally, physically, or financially during the crisis. In fact, the basic tools available for minimizing the spread of COVID-19 in many communities, such as social distancing, masking, and basic hygiene practices, are complicated to implement in some places. This includes homeless camps, correctional facilities, dormitories and other potentially risky facilities within a community.
This type of polarization in community advantage/ disadvantage is all too common in the United States, and the COVID-19 pandemic continues to expose these gaps (Carrión et al., 2020; Douglas \& Subica, 2020). There are many communities where social and economic advantages contribute to various local support structures for their residents. This may include elevated municipal services (e.g., police, fire), healthcare, social services, and infrastructure that supports efficient disaster response (Adger, 2000). However, within this context, it is important to note that communities are infinitely more complex than a simple have/have-not dichotomy based on socio-economic status, education, resilience or the traditional measures of advantage or disadvantage (Archibald \& Putnam Rankin, 2013; Laurence, 2011; M. J. Lynch, 2016). One way to capture a more nuanced understanding of a community's demographic and socio-economic gradients is through geodemographic analysis (Grubesic \& Durbin, 2020; Grubesic et al., 2014; Harris et al., 2005; Singleton \& Longley, 2019).

Geodemography offers the opportunity to generate novel insights and hypothesis generation, particularly related to spatial outcomes that can be further investigated through confirmatory statistical approaches (Grubesic \& Durbin, 2020). In this way, geodemographics should be considered inductive and exploratory rather than deductive and explanatory (Grubesic et al., 2014). This exploratory structure means that geodemographic analysis is highly flexible and widely applicable to public health studies, especially for exploring inequalities associated with health outcomes. For example, Peterson et al. (2011) highlight the utility of geodemographic systems for differentiating neighborhoods for public health campaigns. Moon et al. (2019) use geodemographics to enhance small area estimation of health indicators to limit long-term illness in the U.K., while Bright et al. (2020) use geodemographic segmentation to analyze variations in the risk of emergency presentation of cancer patients in England. In all cases, geodemographics offers an ability to develop an awareness of consumer behavior and lifestyle trends that may play a role in public health outcomeswhich is why it may provide some additional insight into the ecological characteristics of neighborhoods (and their locations) impacted by the COVID-19 pandemic.

Risky and/or noxious facilities

Facilities are either public or private places with some type of infrastructure to facilitate commerce, 
education, recreation, transportation, rehabilitation, and the like (Tompkins, 2010). Risky facilities represent a significant subset of places that generate negative externalities for a community. For example, there is a large corpus of research that documents the impacts of alcohol outlets (i.e., risky facilities) on neighborhoods, including positive and statistically significant increases in assaultive violence in/around alcohol outlet clusters (Grubesic \& Pridemore, 2011; Grubesic et al., 2013; Wei et al., 2020). Noxious facilities, which are easily conflated with risky facilities, are somewhat different. Noxious facilities often produce, consume, or help mitigate some type of hazardous material, such as nuclear fuel, carcinogenic chemicals, or biological waste. Community risks from such facilities often bear a direct relationship to its scale (Ratick \& White, 1988), but the type of hazard such facilities traffic in, also matters. Increasingly, the umbrella of noxious/risky facilities has expanded to include single-room occupancy housing (Krupa et al., 2019), commercial sex premises (Hubbard et al., 2013), halfway houses for sex offenders (Grubesic \& Murray, 2008), pawn shops (Bowers, 2014), and many other types of undesirable places, including correctional facilities (Scott et al., 2018).

The underlying social and geographic problems spawned within communities by these undesirable facilities are many (Greenberg, 2018). For example, in a case study of New York City, Maantay (2001) highlights that noxious facilities and associated landuse tend to concentrate in poor and minority neighborhoods. In Los Angeles, Lejano and Iseki (2001) found geographic concentrations of hazardous waste treatment, storage and disposal facilities in Latino communities. In both instances, there is a disproportionate burden of risk and local impacts from noxious facilities placed on groups of people that may have limited political and economic capital for stimulating reform. These types of environmental injustices are well documented throughout the literature. For a detailed review, see (Nelson \& Grubesic, 2018).

\section{Correctional facilities and COVID-19}

The United States leads the world in total incarcerated population-averaging 2.3 million individuals per day, with the majority ( $\sim 2.1$ million) in federal and state prison systems (Rapisarda et al., 2020). The U.S. confines an additional 740,000 inmates in jail settings on a given day, and nearly 11 million U.S. residents cycle through jail on an annual basis, with an average stay of 25 days (Zeng, 2019). Controlling COVID-19 infections in correctional facilities is critical to "flattening the curve" (Kinner et al., 2020). However, a strict focus on prisoners as carriers and transmitters of infectious diseases means that COVID-19 containment efforts often ignore the potential that correctional staff has to influence infections-both within and outside of prisons. In short, prison staff represents a bi-directional vector of COVID-19 in local communities, capable of spreading infections to/from the prison community and to/from their local residential community (Fig. 1). The fact that as of August, 2020 only about half of the U.S. states were requiring correctional facility staff to wear masks and only one third of states were requiring incarcerated people to wear masks only increases the potential for community outbreaks linked to correctional facility staff (Widra \& Herring, 2020). This process of jailcommunity cycling is also problematic for inmates that have a short stay in a correctional facility. As they cycle back to the local community, they can also spread infections to local residents. For example, recent work by Reinhart and Chen (2020) suggested that people cycling through Cook County Jail (Chicago) accounted for 15.7 percent of all documented COVID-19 cases in Illinois and $15.9 \%$ of all documented cases in the city of Chicago. In this context, the Cook County jail certainly qualifies as a noxious facility. Further, the results suggested that jail-community cycling is a more significant predictor variable than race, poverty, public transit use, or population density. To some degree, a non-peerreviewed report released by the American Civil Liberties Union (ACLU, 2020) corroborates this result. The simulation study suggested that COVID19 fatalities in April 2020 may have been drastically underestimated ( $\sim 98 \%)$ because of poor data from the U.S. correctional system.

While these results are certainly compelling, there are significant limitations and uncertainties associated

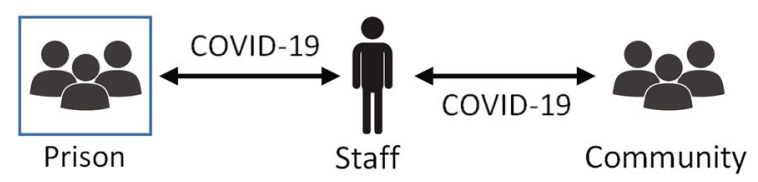

Fig. 1 Jail-community cycling: the role of staff 
with COVID-19 modeling efforts. In particular, efforts to explain or forecast epidemics frequently suffer from insufficient input data, flawed modeling assumptions, high sensitivity of estimates (Ioannidis et al., 2020), and a general lack of important geographic, economic, sociological, political, and/or lifestyle context. These critiques do not suggest that attempts to model COVID-19 are without merit; it simply means that there is a need to improve both the inputs and assumptions-acknowledging modeling limitations and taking care to mitigate them when appropriate (Taleb et al., 2020).

\section{Data and methods}

\section{Study area}

The state of Wisconsin is an interesting location for exploring the geodemographic nuances of COVID-19 and its spread. With approximately 5.8 million residents (Census, 2019), Wisconsin ranks as the 20th most populous U.S. state (Fig. 2). Wisconsin's interstate corridors (I-41, I-43, I-90, I-94) are the most densely settled portions of the state, home to the larger cities of Madison and Milwaukee, as well as smaller, regional hubs such as Green Bay, Appleton, Eau Claire, Janesville, and La Crosse. Much of Wisconsin is rural and agricultural, focusing on dairy farming, corn, and soybeans. However, the northern portions of the state, colloquially referred to as the "Northwoods," is heavily forested and home to a mix of seasonal residences, retirees, and native American tribal lands (Gobster \& Rickenbach, 2004; Loew, 2013). Many of these communities exhibit a lively tourism industry, including places like Rhinelander (Mentzer, 2020), but many others display elevated levels of economic distress (EIG, 2018). The overall demographic profile for Wisconsin in 2019 was $87 \%$ white, $6.7 \%$ black, $7.1 \%$ Hispanic, 3\% Asian, and $1.2 \%$ American Indian, with $10.4 \%$ of Wisconsin's population living in poverty. This demographic mix tracks closely with the $10.5 \%$ U.S. national average. So, while Wisconsin is whiter than the U.S. average (76.3\%), its mix of urban/rural and affluent/impoverished communities represents a study area where the methodology and results presented in this paper could be widely generalizable.
Data

Wisconsin COVID-19 data are collected and maintained by the Wisconsin Department of Health Services (WDHS, 2020) and made available through their associated portal. The data set contains the cumulative daily count of positive and negative cases, deaths, and the age breakdown of the patients. The data are updated daily for all county and census tracts within Wisconsin. Reported cases are laboratoryconfirmed, official state numbers. Reporting began on Mar 15, 2020. WDHS provides unique numerical identifiers for county and census tracts (i.e., GEOID) within the data set.

We obtained the locations of the county, state, and federal correctional facilities within Wisconsin from the Department of Homeland Security's Infrastructure foundation-level data (HIFLD). HIFLD publishes these data with georeferenced information that consists of polygons corresponding to the geographic footprint of each facility. We converted facility footprints to points, and we use only one unique point for each facility (Fig. 2). In addition to the location information, attributes of the correctional facilities included the name of the facility, address, estimated prison population, total capacity, and security level. We use a total of 120 correctional facilities for this analysis, including both prisons/detention centers (52) and jails (68).

We draw our geodemographic data from the Esri Tapestry database (Esri, 2019a,b). The Tapestry segments incorporate a combination of U.S. Census data from 2010, more recent American Community Survey 5-year data (United States Census Bureau, 2019), in-house Esri demographic updates, Experian's ConsumerView data (Experian, 2019), and an extensive range of consumer lifestyle surveys (Gfk MRI, 2019). The Tapestry system represents a typology of 67 unique residential segments that reflect unique lifestyles throughout the United States. We assign each census tract $(n=1,391)$ a dominant tapestry type for the state of Wisconsin. This assignment does not mean that all households fit neatly into these segments. Regardless of geodemographic system quality, there will always be outliers and a range of lifestyles for a given tract. To ensure consistency and stability, Esri uses several ground-truthing processes to verify the viability of assigned lifestyle segments, including independent samples, consumer surveys, and 


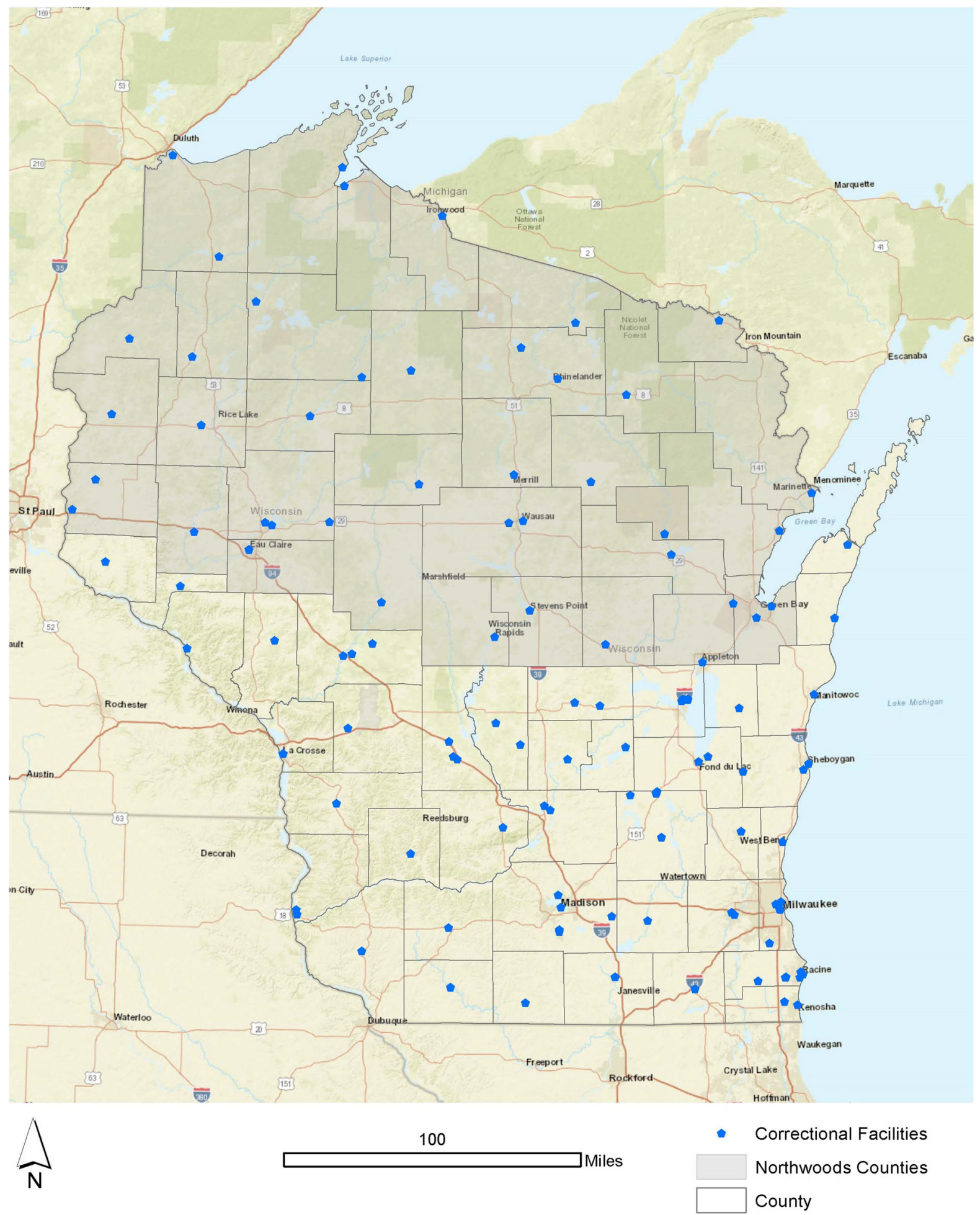

Fig. 2 Correctional facilities in the state of Wisconsin, 2020 
information on spending patterns, service brand usage, and media preferences (ESRI, 2015).

\section{Methods}

All of the reported COVD-19 case information from WDHS (2020) arrived in CSV format. In addition to the cumulative case count reported within the WDHS data, we derive the count of new daily cases for each tract by subtracting the previous day's case count from the current day's case count. Cases were assigned to each tract using the unique GEOID identifier. Where applicable, infection rates were derived using daily cases at time $(t)$ for each census tract $(i)$ per 10,000 residents as follows:

Rate $_{i}^{t}=\left(\frac{{\text { daily } \text { cases }_{i}^{t}}_{\text {population }_{i}}}{\text { ppu }} * 10,000\right.$

This simple calculation provides the ability to objectively compare COVID-19 infection rates between both rural and urban tracts in an unbiased manner.

In addition to basic cartographic analysis, we utilize several more advanced statistical methods to deepen our understanding of the COVID-19 dynamics in the state of Wisconsin. First, we apply the local Moran's I statistic (Anselin, 1995):

$I_{i}=z_{i} \sum w_{i j} z_{j}$

where $x_{i}$ and $x_{j}$ are observations for tracts $i$ and $j$ (with mean $\left.\mu), z_{i}=\left(x_{i}-\mu\right), z_{j}=x_{j}-\mu\right)$, and $w_{i j}$ is a spatial weights matrix with values of 0 or 1 , based on queen's contiguity. However, rather than using the standard Local Moran's I statistic (2), it is implemented with Empirical Bayes (EB) rates (Assunção \& Reis, 1999). The EB standardization procedure standardizes raw rates to obtain a constant variance via rescaling. This variation means replacing the raw rate with a standardized rate $($ mean $=0, \mathrm{SD}=1)$. This process helps reduce instability in the Local Moran's I measure and minimizes the potential for spurious inference. We use tract population for the EB standardization process.

We also leverage a retrospective space-time analysis that scans for clusters of tracts that exhibit higher than expected rates (Kulldorff, 1997; Kulldorff \& Nagarwalla, 1995). The spatial scan statistic is a classic approach that uses a cylindrical window with a circular geographic base. The height of the cylinder corresponds to time and reflects any possible time interval of less than (or equal to) half of the total study period-and the study period as a whole. Each of the generated scanning windows is moved in space and time to cover the entire study region. Each cylinder represents a possible cluster, and COVID-19 infections are assumed to be Poisson distributed with a constant risk over space and time. This approach captures the number of cases both inside/outside the scanning cylinder during the scanning process. When combined with the expected number of cases reflecting the underlying population at risk, it calculates the likelihood for each cylinder. We tag the cylinder with the maximum likelihood (exhibiting more than its expected number of cases) as a hot spot. We evaluate significance with Monte Carlo simulation, where the null hypothesis (i.e., no clusters) is rejected at an $\alpha=0.05$ if the simulated $P$ is less than or equal to 0.5 for the most likely cluster (Kulldorff et al., 1998). We conducted all space-time scan statistics with SaTScan v. 9.6.1. Analysis began with the first day of case reporting at the census tract level (Apr 11, 2020) and ended on Oct 1, 2020. Maximum cluster size was limited to $10 \%$ of the population at risk, and the temporal window included a minimum size of 5 days, with a maximum of $50 \%$ of the study period. Finally, the clusters were restricted to include a minimum of five cases for a hot spot, and no geographical overlap was allowed. ${ }^{2}$

For this paper, drive-time catchment areas for correctional facilities are used to benchmark, assess, and evaluate the influence of community proximity (i.e., census tracts) to each location. We calculated catchment areas for each correctional facility using a suite of geocomputational procedures. Schuurman et al. (2006) detailed that catchments are geographical areas around an institution or business that helps describe the population that may use its services. For example, drive-time catchment areas are used widely

\footnotetext{
${ }^{2}$ Because many of the underlying parameters are somewhat subjective, sensitivity analysis was conducted-varying cluster membership thresholds, as well as geographic and temporal windows. Local contextual knowledge of the state and its infection rates were also incorporated into the sensitivity analysis. The reported results represent the best balance of parameter selections for generating spatiotemporally stable hotspots of COVID-19 infections for Wisconsin during the study period.
} 
by retailers to deepen their understanding of local market demographics, evaluate store accessibility, and target promotional efforts to potential customers (Clarkson et al., 1996; Dolega et al., 2016). We generate geographic catchment areas using 5, 10, and 15-min drive-times on the local street network. These catchment areas reflect typical travel times, but do not account for high-traffic scenarios such as rush hour (7 am-9 am or 4 pm-6 pm) for major metropolitan areas. Figure 3 displays the 10-min drive-time catchment areas for each of the correctional facilities. Compared to the 10-min catchments, the 5-min are more geographically compact, while the 15 -min are more geographically expansive.

Finally, we leverage a two-sample $t$-test for comparing the infection rates for each tract and their relative proximity to correctional facilities as defined by the 5,10 , and 15-min catchment areas detailed above. Large differences between the mean infection rates in areas inside/outside the catchment areas may suggest a disproportionate burden of COVID-19 risk for communities proximal to the corrections facilities. Because the data in Wisconsin exhibited heteroscedasticity (i.e., tracts inside and outside the catchment areas have different standard deviations), we use Welch's $t$-test (Welch, 1947) following a significant Levene's test statistic.

\section{Results}

Spatial and space-time clusters

Figure 4 displays the cumulative infection rate for COVID-19 cases in Wisconsin between April and October 2020. Readers need to note that the geographic extent of census tracts in Wisconsin varies substantially. As a result, it is easy to miss the high infection rates for the smaller tracts in the Milwaukee, Madison, Racine, and Kenosha areas in southeastern Wisconsin. Elsewhere in the state, it is clear that many of the smaller, regional urban centers such as Green Bay, La Crosse, Appleton, and Eau Claire exhibited high rates of infection. In fact, the highest overall infection rate at the tract level was in the Green Bay area (2751 per 10,000). For much of rural Wisconsin, COVID-19 was undoubtedly present, but the overall infection rates were much lower. These lower rates included much of west-central Wisconsin and portions of the Northwoods. For example, a census tract located in Ladysmith, Wisconsin (Rusk County) had the lowest infection rate in the state for the study period, 20.09 cases per 10,000 .

We applied the Local Moran's I test with Empirical Bayes standardization to identify local spatial clusters and disambiguate tract infection rates. Figure 5 displays the results. Of particular note are the highhigh and high-low tracts. ${ }^{3}$ The Moran's $I$ statistic for this analysis was 0.189 , suggesting a low but statistically significant $(0.05 \%)$ level of spatial autocorrelation in the data. ${ }^{4}$ In sum, of the 1390 tracts used for analysis, $120(8.63 \%)$ were classified as COVID-19 hot-spots (high-high), 320 (23.02\%) were classified as cold-spots (low-low), $11(0.79 \%)$ as cool-spots (lowhigh) and $9(0.64 \%)$ as warm-spots (high-low).

In addition to the hot spots in/around Milwaukee, Madison, Kenosha, and Racine, it is notable that many of the communities that are home to a regional campus of the University of Wisconsin system emerged as hot spots in the analysis. These hot spots include Eau Claire, La Crosse, and the city of Whitewater. Where the latter is concerned, Whitewater is a much smaller community $(\sim 15,000$ permanent residents $)$ when compared to Eau Claire $(\sim 65,000)$ and La Crosse $(\sim 50,000)$. However, when the University of Wisconsin-Whitewater is in session, the local population swells by the addition of 12,000 students-effectively doubling the size of the city.

The space-time scan statistic provides an alternative method for identifying hot spots of the COVID-19 outbreak in Wisconsin (Fig. 6). By incorporating a temporal component, it is possible to identify the start and end date of each hot spot (Table 1). In addition, Table 1 provides information on the relative risk, statistical significance, and strength (LLR) for each space-time hot-spot. There are several important outcomes highlighted in this table. First, the outbreak in Madison, which started during the first week of September and ended in the third week, was the most severe event in the state. Centered on the University of

\footnotetext{
${ }^{3}$ High-high tracts are those with high rates of infection surrounded by tracts of similarly high rates. High-low tracts are those with high rates of infection surrounded by tracts of much lower rates.

${ }^{4}$ When the local Moran's I is conducted without EB standardization, $I=0.511$ and the test generates a nearly identical spatial footprint of clusters.
} 


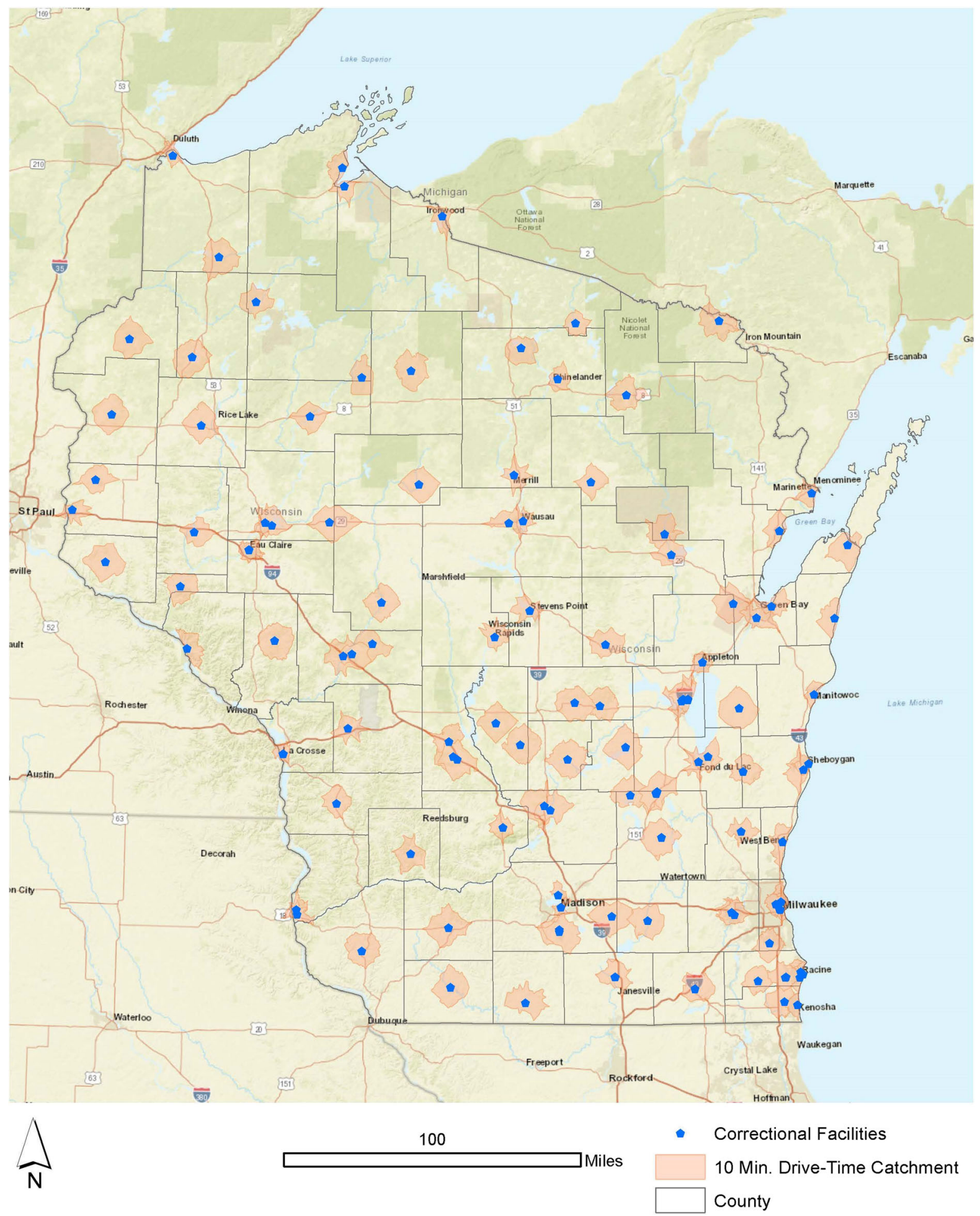

Fig. 3 10-min drive-time catchment areas for correctional facilities in Wisconsin 


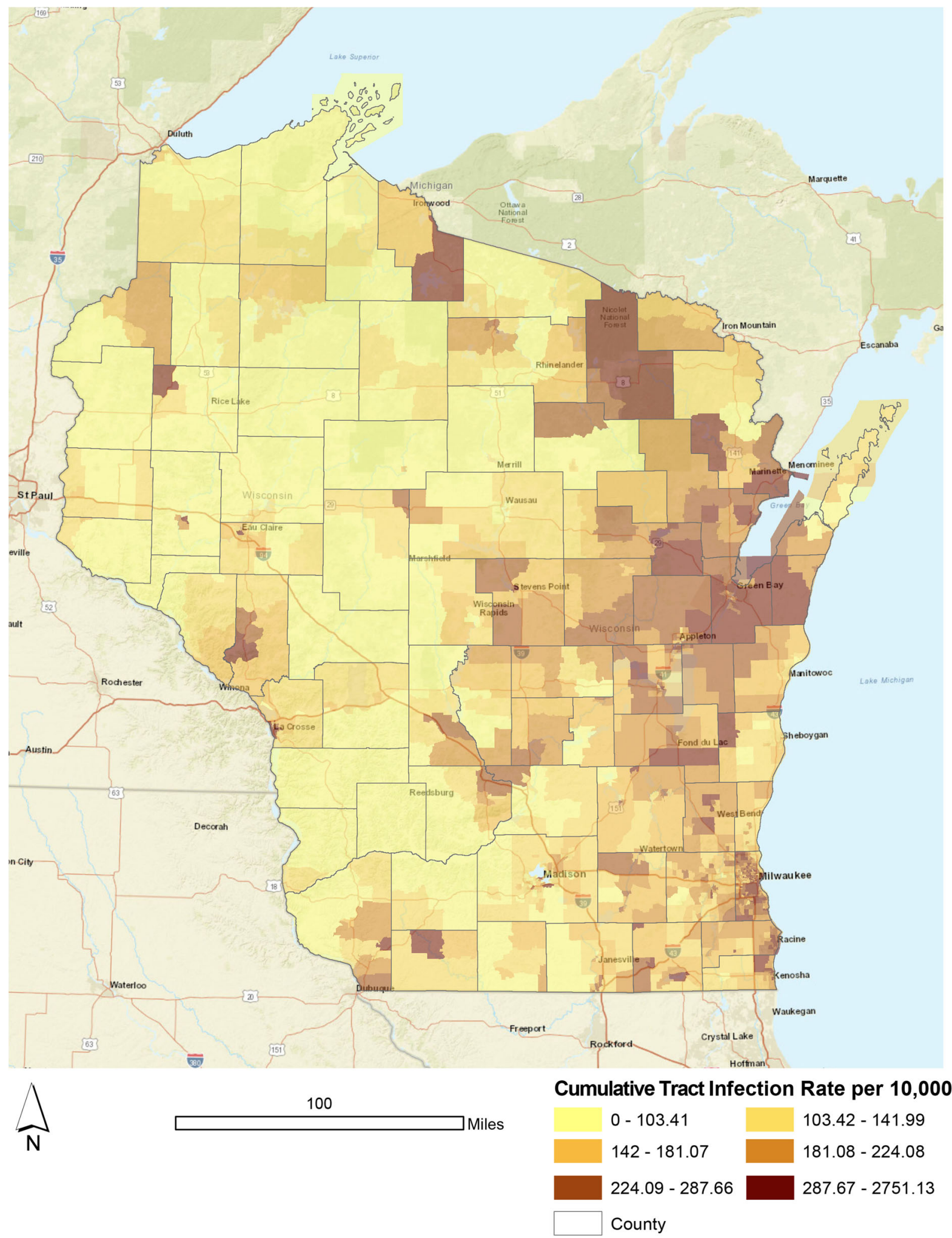

Fig. 4 COVID-19 infection rates by Tract, April-October, 2020 


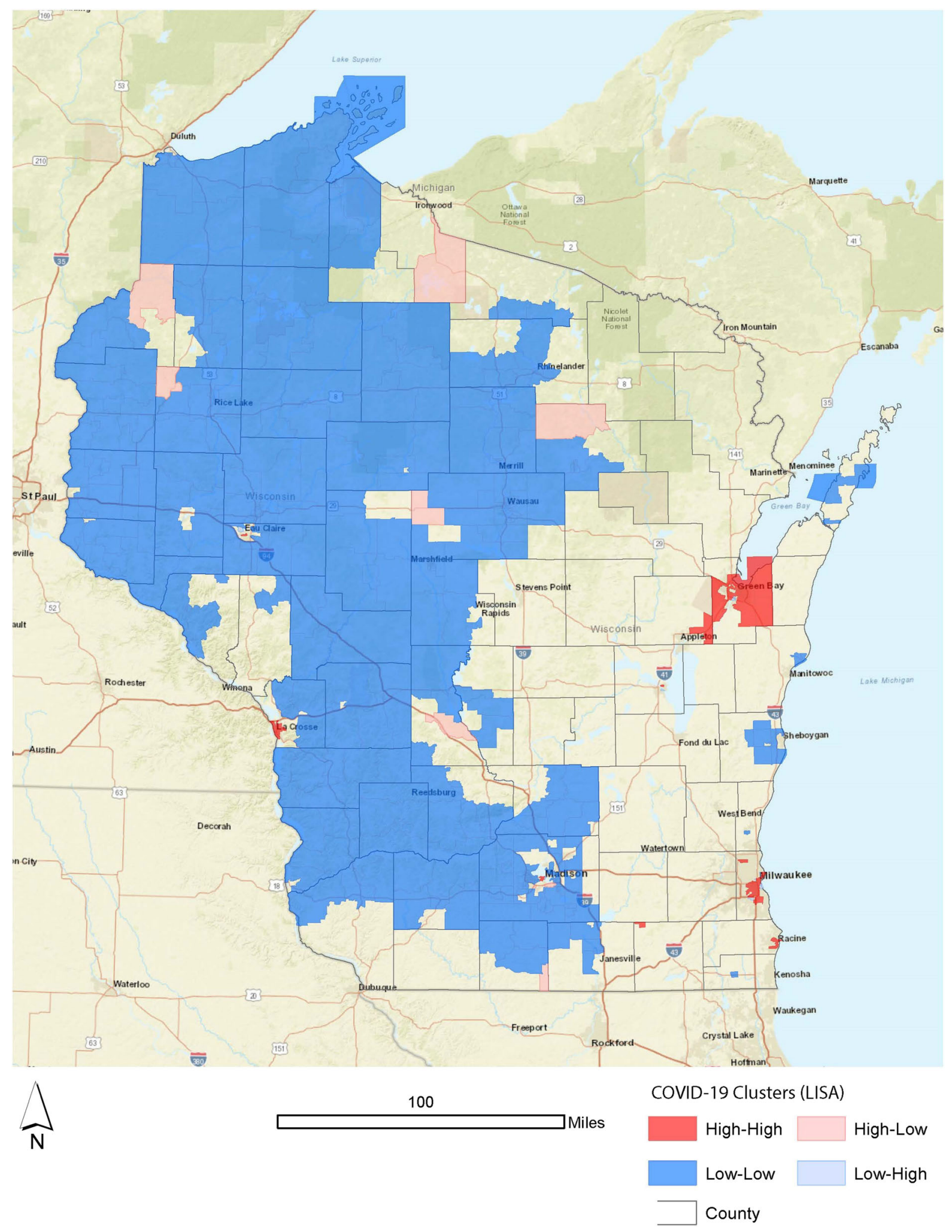

Fig. 5 Local Moran's 1 hot-spots of COVID-19 infections, April-October, 2020 

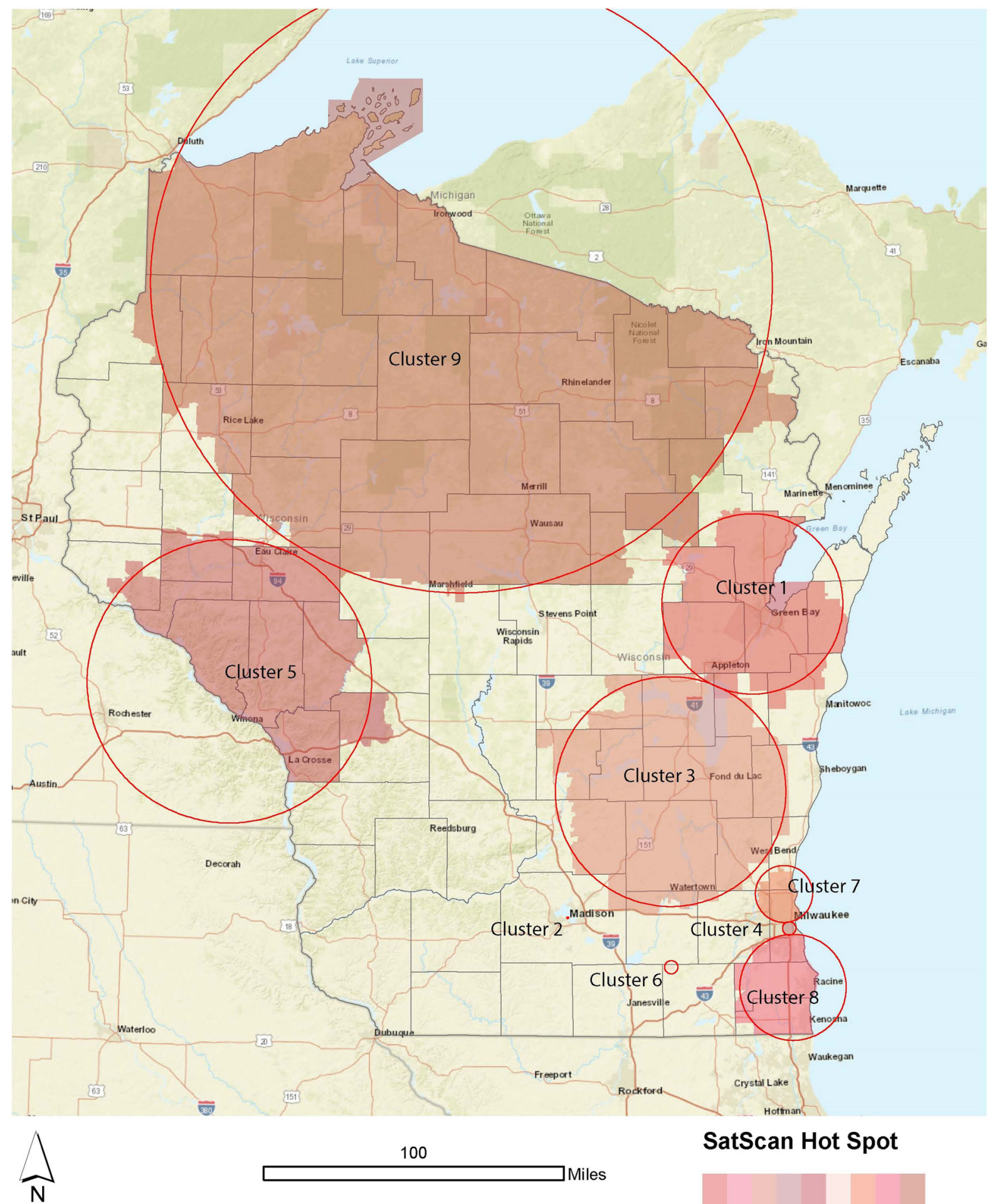

SatScan Hot Spot

100

Miles

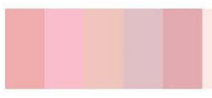

County

Fig. 6 Space-time hot-spots of COVID-19 infections 


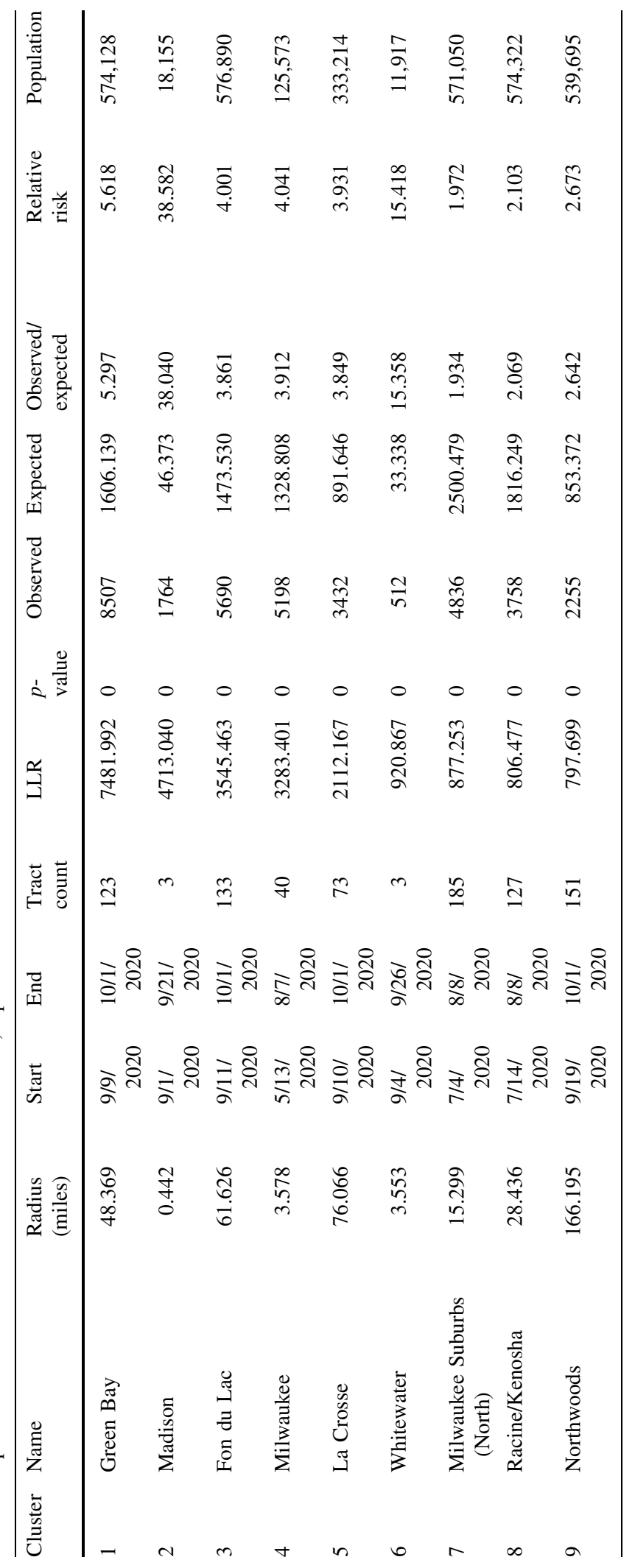




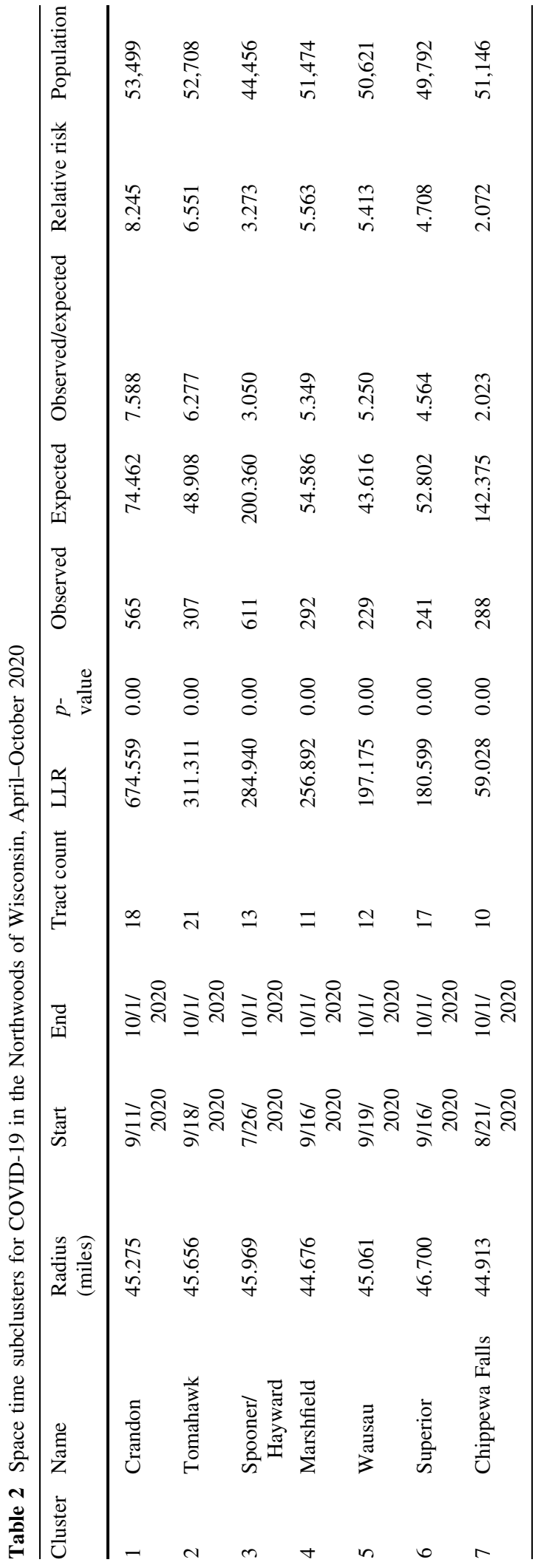

Wisconsin-Madison campus, the university started classes on Sept 2, and by the fifth day of classes, the campus reported 404 infections (Meyerhofer, 2020). This outbreak prompted a two-week lockdown for large dormitories and a campus-wide pause for faceto-face instruction. The space-time statistic results detailed here suggest that the partial shutdown may have helped mitigate the outbreak for Madison. Second, the outbreaks for Whitewater, La Crosse/ Eau Claire, and Green Bay have similar start dates and share large regional campuses for the UW system. As detailed in Table 1, the outbreak in Whitewater was particularly acute, where relative risk was concerned.

The space-time hot-spot in the Northwoods is of interest. From a geographic perspective, it is the largest of the nine hot spots. However, given the way that SatScan operates, this result should be interpreted with some caution. Because the Northwoods region has a low population density, SatScan can collect more tracts for statistical analysis without exceeding the selected population threshold for the test statisticthereby generating a geographically expansive hotspot. However, it is possible to provide some additional fidelity to the Northwood cluster by generating sub-clusters with SaTScan. Specifically, all of the tracts in Cluster 9 were subjected to a secondary space-time analysis to create sub-clusters for the region (Table 2). The results suggested a robust geographic correspondence between many hot spots in the Northwoods and tribal lands (Fig. 7). In addition, Table 2 shows that many of these outbreaks started in September and continued through the end of our study period (October), corroborating local reporting and tribal vulnerabilities to the virus (A.P., 2020).

Geodemographic trends in the COVID-19 outbreak

Figure 8 illustrates the cumulative COVID-19 case rate by geodemographic LifeMode groups using the Esri Tapestry segmentation system. LifeMode groups are markets that share a common experience (Esri, 2019a). This experience may be age-related (e.g., born in the same generation), related to migratory roots (e.g., country of origin), or some type of significant demographic trait, such as income. There are 14 LifeMode groups that serve as an umbrella for the 67 unique market segments. 


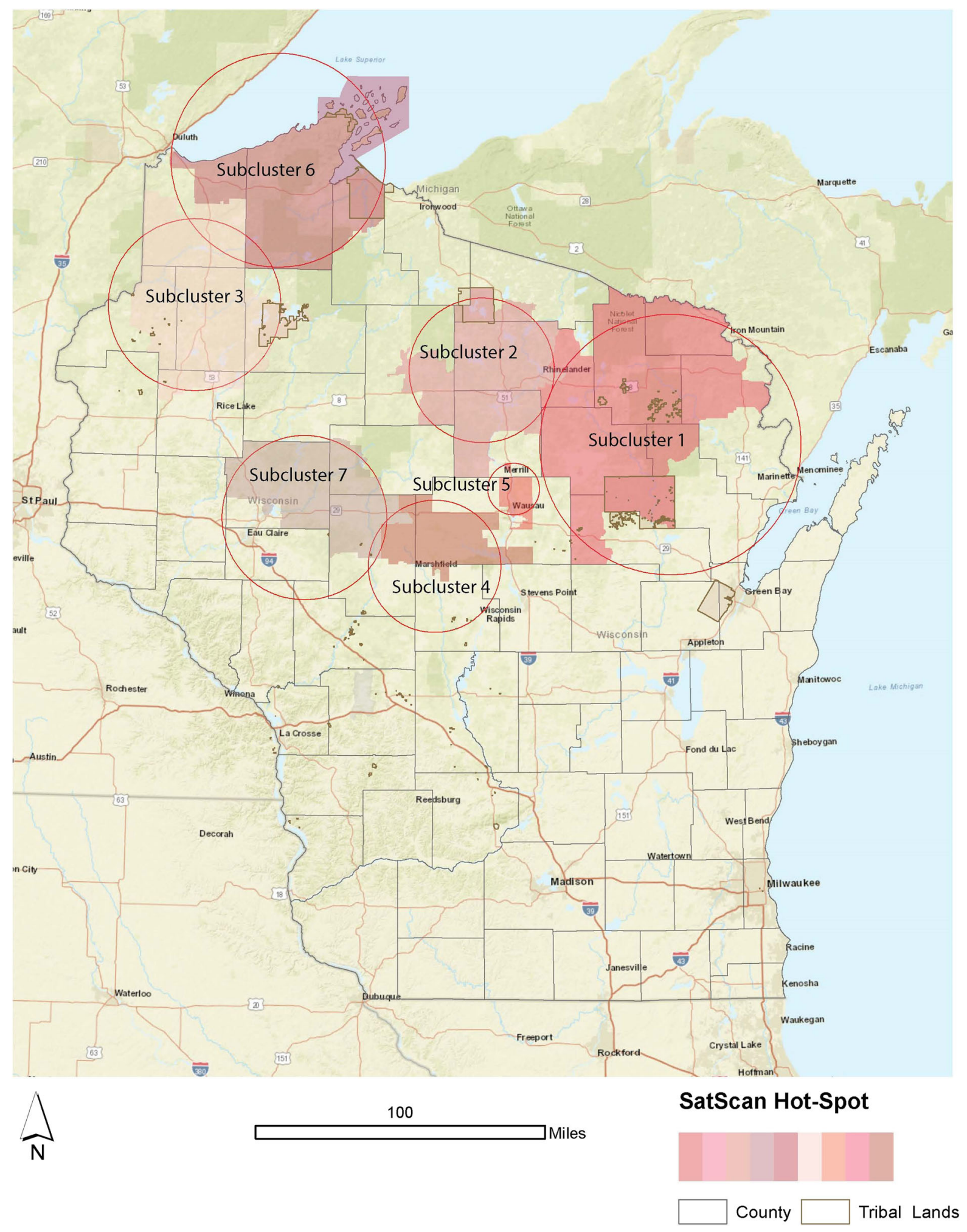

Fig. 7 Space-time hot-spot subclusters and tribal lands, Northwoods Wisconsin 


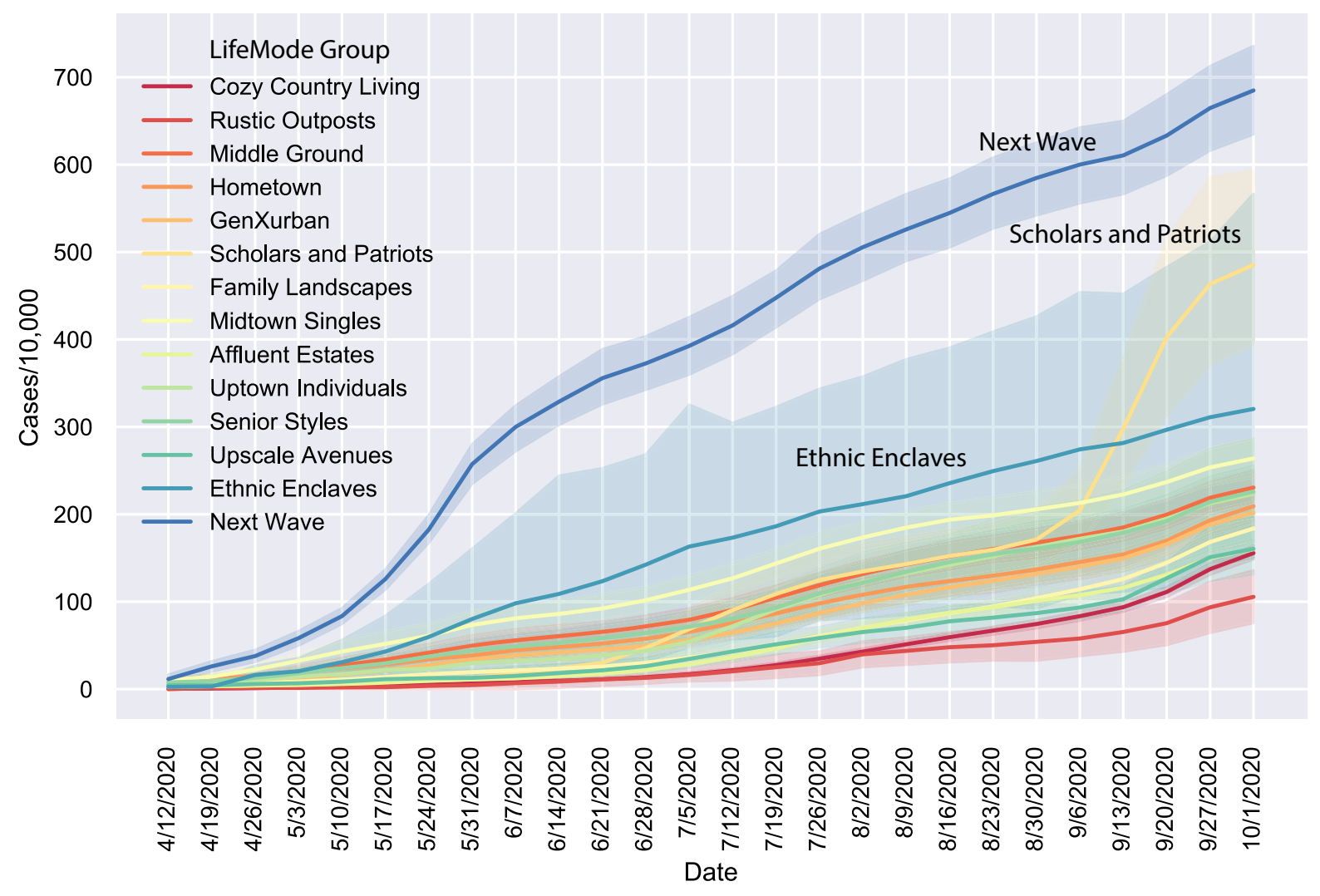

Fig. 8 Cumulative COVID-19 case rates by LifeMode group

Each of the lines plotted in Fig. 8 corresponds to the mean value of the tracts for a LifeMode group. The corresponding bands represent the $95 \%$ confidence interval for those values for that set of tracts. Three groups, Next Wave, Scholars and Patriots, and Ethnic Enclaves displayed a substantially higher infection rate for the study period. In particular, Next Wave started with the highest case rate and remained that way through October. Nationally, this LifeMode group is predominantly Hispanic, with many working in the service or construction industry. Median incomes are lower than the national average, and most of the residents in this group never graduated high school. This profile is certainly the case for Next Wave tracts in Wisconsin. Statewide, the Next Wave tracts averaged $72.8 \%$ Hispanic, with median incomes averaging $\$ 32,775$. Of note, $20.2 \%$ of the residents in these tracts in Wisconsin do not have health insurance. All 27 tracts classified as Next Wave in Wisconsin are located in a detected hot spot, with a mean case rate (684.45) almost three times higher than the state average for tracts (209.38).
Of particular interest in Fig. 8 is the Scholars and Patriots group, which displayed a massive uptick in COVID-19 infection rates in early September. Again, we typically find this LifeMode in college and/or military towns throughout the United States. In the state of Wisconsin, this included the hot-spots centered on Fon du Lac (U.W. Oshkosh), Green Bay (U.W. Green Bay), Milwaukee (U.W. Milwaukee), Madison (U.W. Madison), La Crosse/Eau Claire (U.W. Eau Claire, U.W. La Crosse, and U.W. Stout) and Whitewater (U.W. Whitewater). In short, while accounting for less than $3 \%(n=41)$ of the total tracts in the state, Scholars and Patriots is linked to six of the nine detected space-time hot-spots. The underlying geodemographic segments (College Towns and Dorms to Diplomas) include primarily nonfamily households with students living alone or with roommates in densely developed student housing. Interestingly, there are other areas in the state with tracts in these segments (e.g., Platteville, Stevens Point, and River Falls) that also have a U.W. system campus present but were not designated hot-spots during the study period. 
Lastly, the Ethnic Enclaves LifeMode group exhibited the third-highest average case rate (320.51) at the end of the study period. There are only four census tracts classified in this group for the entire state, with two located in Madison, one in Delavan, and one in Milwaukee (hot-spot Cluster 4). The Milwaukee tract (geodemographic segment; Barrios Urbanos) absolutely overwhelms the remaining three tracts with population-adjusted case counts. For example, during the last week of the study period (October), there were 624.56 cases per 10,000 residents. The next highest was in Delevan, with 340.44. The remaining tracts were both below 200 cases per 10,000 . This trend was present throughout the entire study period, with the Milwaukee tract exhibiting $100 \%$ or more cases than the others in the Ethnic Enclaves LifeMode group. Notably, the tract in Milwaukee is located in one of the most segregated neighborhoods in the state, with a history of public health concerns (Lynch \& Meier, 2020).

Correctional facilities and COVID-19

in Wisconsin

To deepen our understanding of the connection between correctional facilities and the COVID-19 outbreak in Wisconsin, we created two groups of census tracts-those found within the 5,10 , or 15 -min drive time catchments and those that are not. This binary classifier helped identify variations in case rates throughout the state by accounting for geographic proximity to the risky facilities. The resulting Welch's $t$-test of mean case rates between the groups exhibited a consistent and nearly ubiquitous series of outcomes. Mean COVID-19 case rates are higher in tracts proximal to correctional facilities when compared to those that are not (Table 3). Further, the plot of cumulative case rates, over time, with respect to the number of correctional facilities within the catchment area, suggests that as the number of facilities increases, so too does the population-adjusted case rates. For example, consider Fig. 9, which highlights that tracts within $10 \mathrm{~min}$ of three, four, or five correctional facilities have higher case rates at all points in the study period. In all instances, these tracts exhibited average case rates approaching (or exceeding) 300 per 10,000 people. Conversely, tracts with less exposure to these risky facilities exhibited much lower population-adjusted case rates. The same trend
Table 3 Two-sample t-test for equality of COVID-19 case rates within correctional facility catchment areas in Wisconsin, April-October, 2020

\begin{tabular}{|c|c|c|c|c|}
\hline \multirow[t]{2}{*}{ Week } & \multirow[t]{2}{*}{ Date } & \multicolumn{3}{|l|}{ t-statistic } \\
\hline & & 5-Minute & 10-Minute & 15-Minute \\
\hline 1 & 04_12 & $3.54613 * * *$ & $3.36648 * * *$ & $7.61522 * * *$ \\
\hline 2 & 04_19 & $3.53879 * * *$ & $4.54252 * * *$ & $8.43672 * * *$ \\
\hline 3 & $04 \_26$ & $3.69572 * * *$ & $5.50535 * * *$ & $9.43263 * * *$ \\
\hline 4 & 05_03 & $3.81836 * * *$ & $6.78286 * * *$ & $10.63152 * * *$ \\
\hline 5 & 05_10 & $3.61331 * * *$ & $7.14669 * * *$ & $11.19534 * * *$ \\
\hline 6 & 05_17 & $3.67789 * * *$ & $7.35362 * * *$ & $11.73809 * * *$ \\
\hline 7 & 05_24 & $3.80383 * * *$ & $7.84904 * * *$ & $12.88244 * * *$ \\
\hline 8 & 05_31 & $3.56731 * * *$ & $7.50488 * * *$ & $13.18739 * * *$ \\
\hline 9 & 06_07 & $3.67425 * * *$ & $7.60041 * * *$ & $13.15073 * * *$ \\
\hline 10 & 06_14 & $3.23456 * * *$ & $7.46929 * * *$ & $13.53679 * * *$ \\
\hline 11 & 06_21 & $3.16264 * * *$ & $7.45763 * * *$ & $13.65178 * * *$ \\
\hline 12 & 06_28 & $3.38105 * * *$ & $7.69008 * * *$ & $14.07408 * * *$ \\
\hline 13 & 07_05 & $3.49255^{* * *}$ & $7.81848 * * *$ & $14.32494 * * *$ \\
\hline 14 & 07_12 & $3.81834 * * *$ & $8.0199 * * *$ & $14.6314 * * *$ \\
\hline 15 & 07_19 & $3.74997 * * *$ & $8.02194 * * *$ & $14.76292 * * *$ \\
\hline 16 & 07_26 & $3.51755 * * *$ & $7.82333 * * *$ & $14.59451 * * *$ \\
\hline 17 & 08_02 & $3.34132 * * *$ & $7.72122 * * *$ & $14.22962 * * *$ \\
\hline 18 & 08_09 & $3.2109 * *$ & $7.55428 * * *$ & $14.02563 * * *$ \\
\hline 19 & 08_16 & $3.30813 * *$ & $7.40046 * * *$ & $13.66347 * * *$ \\
\hline 20 & 08_23 & $3.10533 * *$ & $7.07397 * * *$ & $13.26084 * * *$ \\
\hline 21 & 08_30 & $3.00036^{* *}$ & $6.90767 * * *$ & $12.90243 * * *$ \\
\hline 22 & 09_06 & $2.9318 * *$ & $6.84304 * * *$ & $12.75563 * * *$ \\
\hline 23 & 09_13 & $2.81261 * *$ & $6.71073 * * *$ & $11.86402 * * *$ \\
\hline 24 & 09_20 & $2.49641 *$ & $6.62658 * * *$ & $10.98975^{* * *}$ \\
\hline 25 & 09_27 & $2.14584^{*}$ & $6.67729 * * *$ & $10.69819 * * *$ \\
\hline 26 & 10_04 & 1.85544 & $6.57289 * * *$ & $10.49009 * * *$ \\
\hline
\end{tabular}

p-value: $*<0.05, * *<0.01, * * *<0.001$

exists for the 15 -min catchment areas (not shown). ${ }^{5}$ The 5-min catchment provided a slight exception, where tracts proximal to four different correctional facilities had the second-lowest case rate. However, it is important to remember that the 5-min catchments are highly compact, drastically shrinking the total number of observations.

\footnotetext{
5 This relationship is also stable in rural, lower density areas. Specifically, plots of the relationship between case rates and correctional facilities for tracts with population less than 400 people per square mile suggested that proximity to the risky facilities increases case counts for tracts.
} 
Fig. 9 Cumulative COVID19 case rates for tracts within $10 \mathrm{~min}$ of a correctional facility

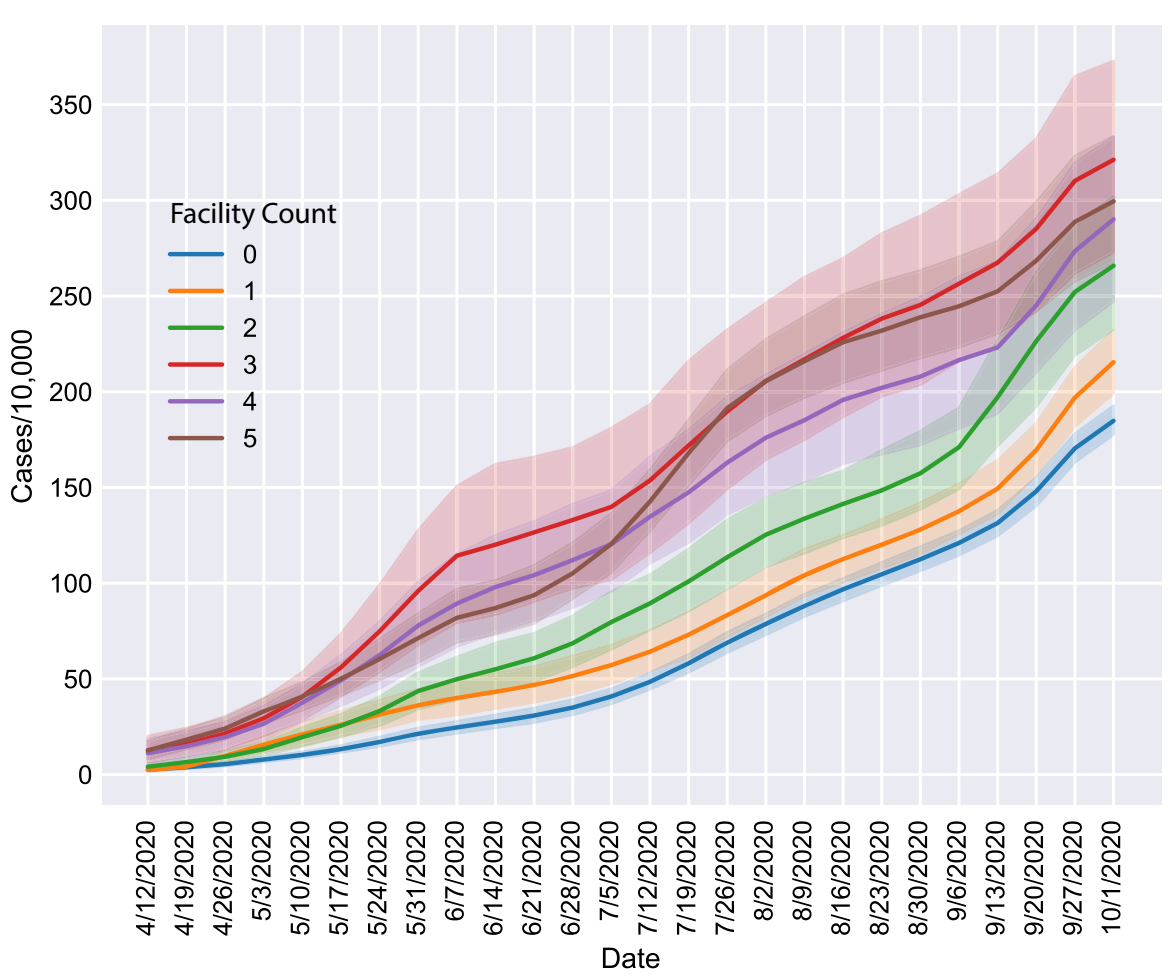

\section{Discussion, limitations and conclusions}

There are three facets of the results worth additional discussion. First, many of the worst COVID-19 hot spots in Wisconsin were connected to university communities throughout the state. The spikes in case rates for these tracts perfectly corresponded to the return of students to these communities in early September. As noted above, while the partial lockdown of the U.W. campus in Madison seemed to flatten the curve locally (Meyerhofer, 2020), our study period ended in early October, and there may have been some additional spikes we did not capture in the university communities later in the autumn. Second, it is important to acknowledge that COVID-19 testing plays a role in these numbers. While the data from WHDS represents the best, publicly available information, WHDS likely failed to include many COVID19 cases in these tabulations-particularly in university communities. Nationally, some schools required testing for all students, once per week, if they wanted to remain on campus, while at other schools, students with symptoms had difficulty getting tested (Courage, 2020). The University of Wisconsin system includes two doctoral research universities (Madison and
Milwaukee), eleven comprehensive universities (e.g., Whitewater), and thirteen freshman-sophomore branch campuses-all of which handled the COVID19 outbreak on their campus independently. This variation in testing may explain why campuses such as Stevens Point, Platteville and River Falls were not included in any space-time hot spots. Regardless, it is likely that the numbers reported in this paper and the corresponding hot spots represent a conservative estimate of the outbreak.

Second, the results strongly suggest that the COVID-19 outbreak in Wisconsin disproportionately impacted certain groups of people. In addition to the acute outbreaks in university communities, the geodemographic analysis of COVID-19 in Wisconsin suggests that many of the predominantly Hispanic and American Indian communities throughout the state suffered. For example, the Next Wave LifeMode group, characterized by undereducated, poor, and largely Hispanic populations, exhibited higher case rates than any other geodemographic group. All 27 of the tracts in Wisconsin classified as Next Wave were located in Milwaukee and Racine and were significant contributors to the Cluster 4 and Cluster 8 hot-spots 
(Fig. 6). In addition, all 27 of these tracts were within a ten-minute drive of at least one correctional facility.

At the same time, tribal populations throughout the Northwoods region of Wisconsin were also disproportionately impacted by the COVID-19 outbreak. Figure 7 illustrated the geographic correspondence between the Northwoods sub-cluster hot-spots and tribal lands, but it is also important to acknowledge that the hot-spot detected in Green Bay (Fig. 6) included the Oneida Nation. In fact, the Oneida tribal land in Green Bay included portions of two high-high clusters detected by the Local Moran's I statistic. In short, the results presented in this paper corroborate early empirical results that suggest COVID-19 disproportionately impacts racial and ethnic minorities throughout the United States (Tai et al., 2020).

Finally, the empirical results of this paper suggest that there may be a connection between the presence of correctional facilities and elevated COVID-19 case rates in proximal communities. As detailed in Table 3, there is strong statistical evidence that tracts located within 5,10 , and $15 \mathrm{~min}$ of a correctional facility exhibited higher case rates when compared to tracts that were not in these catchment areas. Further, visual evidence (Fig. 9) suggested that tracts proximal to more correctional facilities exhibited higher case rates when compared to tracts proximal to fewer facilities. This finding held for rural areas too. While more mathematical and statistical modeling is required to uncover the exact nature of this connection, the concept of jail-community cycling is undoubtedly relevant for Wisconsin. Again, inmates often have a relatively short stay in jails, and as they cycle back to the local community (i.e., areas proximal to the facility), they have the potential to spread infections to local residents. This dynamic was certainly the case for Cook County Jail in Illinois (Reinhart \& Chen, 2020) and may be true for communities throughout Wisconsin. Further, community residents that work in the corrections system and the local incarcerate facilities might (unknowingly) bring the COVID-19 infections home. More work is required to establish this connection.

\section{Limitations}

There are several limitations to our analysis worth noting. First, as mentioned in the introduction, geodemographic analysis is exploratory by nature.
As a result, it is difficult to isolate the exact lifestyle preferences that make certain groups more "at risk" for COVID-19 infections. However, our study does suggest that the spatial distribution of three groups (Next Wave, Scholars and Patriots, and Ethnic Enclaves) displayed a substantially higher infection rate for the study period. There is real analytical value in this result. The collective vulnerability of these groups allows public health officials to prospectively identify these geodemographic segments in other locations (e.g., outside of Wisconsin) and potentially prioritize local public health efforts in these communities, especially those with risky facilities nearby. More work is required to understand the nuances of each group's lifestyle and its relationship to COVID-19 risk.

Second, our data limits our understanding of the size of correctional facilities. Data on prisons' characteristics and daily functions are notoriously hard to estimate, in large part because of vastly different reporting practices across federal, state, and local prison systems (Committee on the Best Practices for Implementing, 2020). Moreover, within those systems, there may also be different data collection and reporting practices. For example, there are differences in the management of public and private prisons-or prisons that comprise a larger complex where multiple types of prison facilities co-locate (Wallace et al., 2021a,b). For instance, in the federal Bureau of Prisons (BOP), information on privately managed prisons within the BOP, such as prisoner-to-staff ratios, are not reported, making it nearly impossible to understand the staff population throughout the federal prison system (Wallace et al., 2021a,b). Very rarely is data on staff and prisoner populations or characteristics held in place. Moreover, with extensive prison overcrowding and staffing shortages across prisons in the U.S., any numbers concerning the prisoner and staff population are likely in flux. Efforts to understand how and why the lifestyles of these groups facilitate higher infection rates will require more work.

One last limitation to this work is the need to better understand the potential differences between urban and rural relationships between correctional facilities, communities, and COVID-19 risk. While the drivetime catchment areas help standardize this analysis, rural and urban disease transmission dynamics may diverge.

With the arrival of the Pfizer, Moderna, and Johnson \& Johnson vaccines, there is reason to be 
optimistic that the COVID-19 pandemic will soon be over. However, developing a deeper understanding of how COVID-19 established a foothold in the United States and percolated through different institutions (e.g., universities, corrections facilities, etc.), populations (e.g., racial and ethnic minorities) lifestyle groups will require decades of study. Nevertheless, the results of this study suggest that both spatial statistical and geodemographic analysis can provide essential insights into the processes associated with population health and the role of risky facilities.

Funding The study was supported by the National Science Foundation, RAPID award \#2032747.

\section{Declarations}

Conflict of interest The authors declare that they have no conflicts of interest.

Human or animal rights This research did not include any work involving animals. This research does not include any work involving human participants.

\section{References}

A.P. (2020). Coronavirus cases jump among Wisconsin's American Indians. https://apnews.com/article/virusoutbreak-wisconsin-native-americans0e80672c432ed268383ad4199864273b.

ACLU. (2020). COVID-19 model finds nearly 100,000 more deaths than current estimates, due to failures to reduce jails. https://www.aclu.org/sites/default/files/field_document/aclu_ covid19-jail-report_2020-8_1.pdf.

Adger, W. N. (2000). Social and ecological resilience: Are they related? Progress in Human Geography, 24(3), 347-364. https://doi.org/10.1191/030913200701540465

Anselin, L. (1995). Local indicators of spatial association-LISA. Geographical Analysis, 27(2), 93-115. https://doi.org/10. 1111/j.1538-4632.1995.tb00338.x

Archibald, M. E., \& Putnam Rankin, C. (2013). A spatial analysis of community disadvantage and access to healthcare services in the U.S. Social Science \& Medicine, 90, 11-23. https://doi.org/10.1016/j.socscimed.2013.04.023

Assunção, R. M., \& Reis, E. A. (1999). A new proposal to adjust Moran's I for population density. Statistics in Medicine, 18(16), 2147-2162. https://doi.org/10.1002/(sici)10970258(19990830)18:16\%3c2147::aid-sim179\%3e3.0.co;2-i

Babore, A., Lombardi, L., Viceconti, M. L., Pignataro, S., Marino, V., Crudele, M., Candelori, C., Bramanti, S. M., \& Trumello, C. (2020). Psychological effects of the COVID2019 pandemic: Perceived stress and coping strategies among healthcare professionals. Psychiatry Research, 293, 113366. https://doi.org/10.1016/j.psychres.2020.113366

Baker, S., Bloom, N., Davis, S., \& Terry, S. (2020). COVIDInduced Economic Uncertainty (No. w26983; p. w26983).
National Bureau of Economic Research. Doi: https://doi. org/10.3386/w26983.

Barberia, L. G., \& Gómez, E. J. (2020). Political and institutional perils of Brazil's COVID-19 crisis. The Lancet, 396(10248), 367-368. https://doi.org/10.1016/S01406736(20)31681-0

Bavel, J. J. V., Baicker, K., Boggio, P. S., Capraro, V., Cichocka, A., Cikara, M., Crockett, M. J., Crum, A. J., Douglas, K. M., Druckman, J. N., Drury, J., Dube, O., Ellemers, N., Finkel, E. J., Fowler, J. H., Gelfand, M., Han, S., Haslam, S. A., Jetten, J., \& Willer, R. (2020). Using social and behavioural science to support COVID-19 pandemic response. Nature Human Behaviour, 4(5), 460-471. https://doi.org/10.1038/s41562-020-0884-z

Bosancianu, C. M., Dionne, K. Y., Hilbig, H., Humphreys, M., Kc, S., Lieber, N., \& Scacco, A. (2020). Political and social correlates of Covid-19 mortality [Preprint]. SocArXiv. https://doi.org/10.31235/osf.io/ub3zd

Bowers, K. (2014). Risky facilities: Crime radiators or crime absorbers? A comparison of internal and external levels of theft. Journal of Quantitative Criminology, 30(3), 389-414. https://doi.org/10.1007/s10940-013-9208-z

Bright, C. J., Gildea, C., Lai, J., Elliss-Brookes, L., \& Lyratzopoulos, G. (2020). Does geodemographic segmentation explain differences in route of cancer diagnosis above and beyond person-level sociodemographic variables? Journal of Public Health. https://doi.org/10.1093/pubmed/fdaa111

Briguglio, L., Cordina, G., Farrugia, N., \& Vella, S. (2009). Economic vulnerability and resilience: Concepts and measurements. Oxford Development Studies, 37(3), 229-247. https://doi.org/10.1080/13600810903089893

Brody, S. D., Zahran, S., Vedlitz, A., \& Grover, H. (2008). Examining the relationship between physical vulnerability and public perceptions of global climate change in the United States. Environment and Behavior, 40(1), 72-95. https://doi.org/10.1177/0013916506298800

Camberg, N., Curiskis, A., Goldfarb, A., Kissane, E., Rivera, J. M., Oehler, K., Simon, S., \& Walker, P. (2020). In the deadliest month yet, the pandemic is regional again: This week in COVID-19 data, Dec 23. https://covidtracking. com/analysis-updates/deadliest-month-yet-pandemicregional-again-dec-23.

Carrión, D., Colicino, E., Pedretti, N. F., Rush, J., DeFelice, N., \& Just, A. C. (2020). Assessing capacity to social distance and neighborhood-level health disparities during the COVID-19 pandemic [Preprint]. Public and Global Health. https://doi.org/10.1101/2020.06.02.20120790

Chetty, R., Friedman, J., Hendren, N., Stepner, M., \& Team, T. O. I. (2020). The economic impacts of COVID-19: Evidence from a new public database built using private sector data (No. w27431; p. w27431). National Bureau of Economic Research. Doi: https://doi.org/10.3386/w27431.

Chiu, W. A., Fischer, R., \& Ndeffo-Mbah, M. L. (2020). Statelevel needs for social distancing and contact tracing to contain COVID-19 in the United States. Nature Human Behaviour, 4(10), 1080-1090. https://doi.org/10.1038/ s41562-020-00969-7

Clarkson, R. M., Clarke-Hill, C. M., \& Robinson, T. (1996). UK supermarket location assessment. International Journal of Retail \& Distribution Management, 24(6), 22-33. https:// doi.org/10.1108/09590559610127010 
Committee on the Best Practices for Implementing Decarceration as a Strategy to Mitigate the Spread of COVID-19 in Correctional Facilities, Committee on Law and Justice, Division of Behavioral and Social Sciences and Education, \& National Academies of Sciences, Engineering, and Medicine. (2020). Decarcerating correctional facilities during COVID-19: Advancing health, equity, and safety. E. A. Wang, B. Western, E. P. Backes, \& J. Schuck, (Eds.). National Academies Press. p. 25945 Doi: https://doi.org/ $10.17226 / 25945$.

Courage, K. H. (2020). Why some colleges are winning against Covid-19, and others are losing. Vox. https://www.vox. com/21445908/covid-19-prevention-university-campusdorms-testing.

Cutter, S. L., Boruff, B. J., \& Shirley, W. L. (2003). Social vulnerability to environmental hazards *: Social vulnerability to environmental hazards. Social Science Quarterly, 84(2), 242-261. https://doi.org/10.1111/1540-6237. 8402002

Dietz, W., \& Santos-Burgoa, C. (2020). Obesity and its Implications for COVID-19 Mortality. Obesity, 28(6), 1005-1005. https://doi.org/10.1002/oby.22818

Dolega, L., Pavlis, M., \& Singleton, A. (2016). Estimating attractiveness, hierarchy and catchment area extents for a national set of retail centre agglomerations. Journal of Retailing and Consumer Services, 28, 78-90. https://doi. org/10.1016/j.jretconser.2015.08.013

Douglas, J. A., \& Subica, A. M. (2020). COVID-19 treatment resource disparities and social disadvantage in New York City. Preventive Medicine, 141, 106282. https://doi.org/10. 1016/j.ypmed.2020.106282

Dowd, J. B., Andriano, L., Brazel, D. M., Rotondi, V., Block, P., Ding, X., Liu, Y., \& Mills, M. C. (2020). Demographic science aids in understanding the spread and fatality rates of COVID-19. Proceedings of the National Academy of Sciences, 117(18), 9696-9698. https://doi.org/10.1073/ pnas.2004911117

EIG. (2018). Distressed communities index. Economic innovation group. https://eig.org/dci.

ESRI. (2015). Tapestry segmentation: methodology.

Esri. (2019a). Tapestry segmentation methodology. https:// tinyurl.com/y3j7nt9b.

Esri. (2019d). Tapestry segments. https://tinyurl.com/y4l2hjjj.

Experian. (2019). ConsumerView. https://tinyurl.com/ y56onqvz.

Gfk MRI. (2019). Survey of the American Consumer. https:// tinyurl.com/y5ppyo3z.

Gobster, P. H., \& Rickenbach, M. G. (2004). Private forestland parcelization and development in Wisconsin's Northwoods: Perceptions of resource-oriented stakeholders. Landscape and Urban Planning, 69(2-3), 165-182. https:// doi.org/10.1016/j.landurbplan.2003.09.005

Greenberg, M. R. (2018). Siting noxious facilities: Integrating location economics and risk analysis to protect environmental health and investments. Taylor and Trancis Group: Routledge.

Grubesic, T. H., \& Durbin, K. M. (2020). Geodemographies of breastfeeding support. Journal of Human Lactation. https://doi.org/10.1177/0890334420941416
Grubesic, T. H., \& Murray, A. T. (2008). Sex offender residency and spatial equity. Applied Spatial Analysis and Policy, 1(3), 175-192. https://doi.org/10.1007/s12061-008-9013-5

Grubesic, T. H., \& Pridemore, W. (2011). Alcohol outlets and clusters of violence. International Journal of Health Geographics, 10(1), 30. https://doi.org/10.1186/1476072X-10-30

Grubesic, T. H., Pridemore, W. A., Williams, D. A., \& PhilipTabb, L. (2013). Alcohol outlet density and violence: The role of risky retailers and alcohol-related expenditures. Alcohol and Alcoholism, 48(5), 613-619. https://doi.org/ 10.1093/alcalc/agt055

Grubesic, T. H., Miller, J. A., \& Murray, A. T. (2014). Geospatial and geodemographic insights for diabetes in the United States. Applied Geography, 55, 117-126. https:// doi.org/10.1016/j.apgeog.2014.08.017

Harris, R., Sleight, P., \& Webber, R. (2005). Geodemographics, GIS and neighbourhood targeting. John Wiley \& Sons. http://nbn-resolving.de/urn:nbn:de:101:1-201412187192.

Hohl, A., Delmelle, E. M., Desjardins, M. R., \& Lan, Y. (2020). Daily surveillance of COVID-19 using the prospective space-time scan statistic in the United States. Spatial and Spatio-Temporal Epidemiology, 34, 100354. https://doi. org/10.1016/j.sste.2020.100354

Holtgrave, D. R., Barranco, M. A., Tesoriero, J. M., Blog, D. S., \& Rosenberg, E. S. (2020). Assessing racial and ethnic disparities using a COVID-19 outcomes continuum for New York State. Annals of Epidemiology, 48, 9-14. https:// doi.org/10.1016/j.annepidem.2020.06.010

Hubbard, P., Boydell, S., Crofts, P., Prior, J., \& Searle, G. (2013). Noxious neighbours? Interrogating the impacts of sex premises in residential areas. Environment and Planning A Economy and Space, 45(1), 126-141. https://doi. org/10.1068/a4574

Huynh, T. L. D. (2020). Does culture matter social distancing under the COVID-19 pandemic? Safety Science, 130, 104872. https://doi.org/10.1016/j.ssci.2020.104872

Ioannidis, J. P. A., Cripps, S., \& Tanner, M. A. (2020). Forecasting for COVID-19 has failed. International Journal of Forecasting. https://doi.org/10.1016/j.ijforecast.2020.08. 004

Jin, Y., Yang, H., Ji, W., Wu, W., Chen, S., Zhang, W., \& Duan, G. (2020). Virology, epidemiology, pathogenesis, and control of COVID-19. Viruses, 12(4), 372. https://doi.org/ 10.3390/v12040372

Kinner, S. A., Young, J. T., Snow, K., Southalan, L., LopezAcuña, D., Ferreira-Borges, C., \& O’Moore, É. (2020). Prisons and custodial settings are part of a comprehensive response to COVID-19. The Lancet Public Health, 5(4), e188-e189. 2667(20)30058-X

Krupa, J. M., Boggess, L. N., Chamberlain, A. W., \& Grubesic, T. H. (2019). Noxious housing: The influence of single room occupancy (SRO) facilities on neighborhood crime. Crime and Delinquency. https://doi.org/10.1177/ 0011128719875701

Kulldorff, M. (1997). A spatial scan statistic. Communications in Statistics Theory and Methods, 26(6), 1481-1496. https://doi.org/10.1080/03610929708831995 
Kulldorff, M., \& Nagarwalla, N. (1995). Spatial disease clusters: Detection and inference. Statistics in Medicine, 14(8), 799-810. https://doi.org/10.1002/sim.4780140809

Kulldorff, M., Athas, W. F., Feurer, E. J., Miller, B. A., \& Key, C. R. (1998). Evaluating cluster alarms: A space-time scan statistic and brain cancer in Los Alamos, New Mexico. American Journal of Public Health, 88(9), 1377-1380. https://doi.org/10.2105/AJPH.88.9.1377

Lancet, T. (2020). Redefining vulnerability in the era of COVID-19. The Lancet, 395(10230), 1089. https://doi.org/ 10.1016/S0140-6736(20)30757-1

Laurence, J. (2011). The effect of ethnic diversity and community disadvantage on social cohesion: A multi-level analysis of social capital and interethnic relations in UK communities. European Sociological Review, 27(1), 70-89. https://doi.org/10.1093/esr/jcp057

Lejano, R. P., \& Iseki, H. (2001). Environmental justice: Spatial distribution of hazardous waste treatment, storage and disposal facilities in Los Angeles. Journal of Urban Planning and Development, 127(2), 51-62. https://doi.org/ 10.1061/(ASCE)0733-9488(2001)127:2(51)

Lewnard, J. A., \& Lo, N. C. (2020). Scientific and ethical basis for social-distancing interventions against COVID-19. The Lancet Infectious Diseases, 20(6), 631-633. https://doi. org/10.1016/S1473-3099(20)30190-0

Loew, P. (2013). Indian nations of Wisconsin: Histories of endurance and renewal (2nd ed.). Wisconsin Historical Society Press.

Lynch, M. J. (2016). The ecological distribution of community advantage and disadvantage: Power structures, political economy, communities, and green-state crime and justice. Critical Criminology, 24(2), 247-262. https://doi.org/10. 1007/s10612-016-9313-z

Lynch, E. E., \& Meier, H. C. S. (2020). The intersectional effect of poverty, home ownership, and racial/ethnic composition on mean childhood blood lead levels in Milwaukee County neighborhoods. PLoS ONE, 15(6), e0234995. https://doi. org/10.1371/journal.pone.0234995

Maantay, J. (2001). Zoning, equity, and public health. American Journal of Public Health, 91(7), 1033-1041. https://doi. org/10.2105/AJPH.91.7.1033

Mentzer, R. (2020). Report: Outdoor recreation is worth $\$ 7.8 \mathrm{~B}$ to Wisconsin economy. Wisconsin national public radio. https://www.wpr.org/report-outdoor-recreation-worth-7-8bwisconsin-economy.

Meselson, M. (2020). Droplets and aerosols in the transmission of SARS-CoV-2. New England Journal of Medicine, 382(21), 2063-2063. https://doi.org/10.1056/ NEJMc2009324

Meyerhofer, K. (2020). UW-Madison's fall reopening: A story of success, failure or simply survival? Wisconsin State Journal. https://madison.com/wsj/news/local/education/ university/uw-madisons-fall-reopening-a-story-ofsuccess-failure-or-simply-survival/article_a761d9342fba-533e-8587-06d00ff87245.html.

Moon, G., Twigg, L., Jones, K., Aitken, G., \& Taylor, J. (2019). The utility of geodemographic indicators in small area estimates of limiting long-term illness. Social Science and Medicine, 227, 47-55. https://doi.org/10.1016/j. socscimed.2018.06.029
Moser, W. (2021). The deadliest month yet. The Atlantic. https://www.theatlantic.com/health/archive/2021/02/ january-pandemic-deadliest-month/617898/.

Muñoz-Price, L. S., Nattinger, A. B., Rivera, F., Hanson, R., Gmehlin, C. G., Perez, A., Singh, S., Buchan, B. W., Ledeboer, N. A., \& Pezzin, L. E. (2020). Racial disparities in incidence and outcomes among patients with COVID19. JAMA Network Open, 3(9), e2021892. https://doi.org/ 10.1001/jamanetworkopen.2020.21892

Nazroo, J. Y. (1998). Genetic, cultural or socio-economic vulnerability? Explaining ethic inequalities in health. Sociology of Health and Illness, 20(5), 710-730. https://doi.org/ $10.1111 / 1467-9566.00126$

Nelson, J., \& Grubesic, T. (2018). Environmental justice: A panoptic overview using scientometrics. Sustainability, 10(4), 1022. https://doi.org/10.3390/su10041022

Nepomuceno, M. R., Acosta, E., Alburez-Gutierrez, D., Aburto, J. M., Gagnon, A., \& Turra, C. M. (2020). Besides population age structure, health and other demographic factors can contribute to understanding the COVID-19 burden. Proceedings of the National Academy of Sciences, 117(25), 13881-13883. https://doi.org/10.1073/pnas.2008760117

Patanavanich, R., \& Glantz, S. A. (2020). Smoking is associated with COVID-19 progression: A meta-analysis. Nicotine and Tobacco Research: Official Journal of the Society for Research on Nicotine and Tobacco, 22(9), 1653-1656. https://doi.org/10.1093/ntr/ntaa082

Petersen, J., Gibin, M., Longley, P., Mateos, P., Atkinson, P., \& Ashby, D. (2011). Geodemographics as a tool for targeting neighbourhoods in public health campaigns. Journal of Geographical Systems, 13(2), 173-192. https://doi.org/10. 1007/s10109-010-0113-9

Rapisarda, S. S., Byrne, J., \& Marmolejo, L. (2020). An examination of COVID-19 outbreaks in prisons and jails in North America, Central America, and the Caribbean. Victims and Offenders, 15(7-8), 1234-1243. https://doi.org/ 10.1080/15564886.2020.1835766

Ratick, S. J., \& White, A. L. (1988). A risk-sharing model for locating noxious facilities. Environment and Planning $B$ Planning and Design, 15(2), 165-179. https://doi.org/10. 1068/b150165

Reinhart, E., \& Chen, D. L. (2020). Incarceration and its disseminations: COVID-19 pandemic lessons from Chicago's cook county jail: Study examines how arrest and pre-trial detention practices may be contributing to the spread of COVID-19. Health Affairs, 39(8), 1412-1418. https://doi. org/10.1377/hlthaff.2020.00652

Schuurman, N., Fiedler, R. S., Grzybowski, S. C., \& Grund, D. (2006). Defining rational hospital catchments for nonurban areas based on travel-time. International journal of health geographics, 5(1), 1-11.

Scott, J., Petrossian, G., Mellow, J., \& Peterson, B. (2018). Understanding risky facilities: An analysis of factors associated with jail escapes in eight states. Security Journal, 31(4), 805-820. https://doi.org/10.1057/s41284-0180132-7

Singleton, A. D., \& Longley, P. A. (2019). Data infrastructure requirements for new geodemographic classifications: The example of London's workplace zones. Applied Geography, 109, 102038. https://doi.org/10.1016/j.apgeog.2019. 102038 
Smith, C. D., \& Mennis, J. (2020). Incorporating geographic information science and technology in response to the COVID-19 pandemic. Preventing Chronic Disease, 17, 200246. https://doi.org/10.5888/pcd17.200246

Strully, K., Yang, T.-C., \& Liu, H. (2021). Regional variation in COVID-19 disparities: Connections with immigrant and Latinx communities in U.S. counties. Annals of Epidemiology, 53, 56-62.e2. https://doi.org/10.1016/j.annepidem. 2020.08.016

Tai, D. B. G., Shah, A., Doubeni, C. A., Sia, I. G., \& Wieland, M. L. (2020). The disproportionate impact of COVID-19 on racial and ethnic minorities in the United States. Clinical Infectious Diseases. https://doi.org/10.1093/cid/ciaa815

Taleb, N. N., Bar-Yam, Y., \& Cirillo, P. (2020). On single point forecasts for fat-tailed variables. International Journal of Forecasting. https://doi.org/10.1016/j.ijforecast.2020.08. 008

Thakur, V., \& Jain, A. (2020). COVID 2019-suicides: A global psychological pandemic. Brain Behavior and Immunity, 88, 952-953. https://doi.org/10.1016/j.bbi.2020.04.062

Tompkins, J. A. (Ed.). (2010). Facilities planning (4th ed.). J. Wiley.

United States Census Bureau. (2019). American Community Survey 2014-2018. https://www.census.gov/newsroom/ press-releases/2019/acs-5-year.html.

Velavan, T. P., \& Meyer, C. G. (2020). The COVID-19 epidemic. Tropical Medicine and International Health, 25(3), 278-280. https://doi.org/10.1111/tmi.13383

Wallace, D., Eason, J. M., Walker, J., Towers, S., Grubesic, T. H., \& Nelson, J. R. (2021a). Is there a temporal relationship between COVID-19 infections among prison staff, incarcerated persons and the larger community in the United States? International Journal of Environmental Research and Public Health, 18(13), 6873. https://doi.org/10.3390/ ijerph18136873

Wallace, D., Walker, J., Nelson, J., Towers, S., Eason, J., \& Grubesic, T. H. (2021b). The 2020 coronavirus pandemic and its corresponding data boon: Issues with pandemicrelated DATA from criminal justice organizations. Journal of Contemporary Criminal Justice. https://doi.org/10. $1177 / 10439862211027993$

Wang, B., Li, R., Lu, Z., \& Huang, Y. (2020). Does comorbidity increase the risk of patients with COVID-19: Evidence from meta-analysis. Aging, 12(7), 6049-6057. https://doi. org/10.18632/aging.103000

WDHS. (2020). COVID-19: Wisconsin summary data. Wisconsin department of health services. https://www.dhs. wisconsin.gov/covid-19/data.htm.

Wei, R., Grubesic, T. H., \& Kang, W. (2020). Spatiotemporal patterns of alcohol outlets and violence: A spatially heterogeneous Markov chain analysis. Environment and Planning B Urban Analytics and City Science. https://doi. org/10.1177/2399808320965569

Welch, B. L. (1947). The generalization of 'student's' problem when several different population variances are involved. Biometrika, 34(1/2), 28. https://doi.org/10.2307/2332510

Widra, E., \& Herring, T. (2020). Half of states fail to require mask use by correctional staff. Prison Policy Initiative. https://www.prisonpolicy.org/blog/2020/08/14/masksin-prisons/.

Witte, C., Hungerford, L. L., Rideout, B. A., Papendick, R., \& Fowler, J. H. (2020). Spatiotemporal network structure among "friends of friends" reveals contagious disease process. PLoS ONE, 15(8), e0237168. https://doi.org/10. 1371/journal.pone. 0237168

Zeng, Z. (2019). Jail inmates in 2018 (NCJ 251774; p. 18). Bureau of Justice Statistics. https://www.bjs.gov/content/ pub/pdf/ji17.pdf.

Zhu, G., Xiao, J., Zhang, B., Liu, T., Lin, H., Li, X., Song, T., Zhang, Y., Ma, W., \& Hao, Y. (2018). The spatiotemporal transmission of dengue and its driving mechanism: A case study on the 2014 dengue outbreak in Guangdong, China. Science of the Total Environment, 622-623, 252-259. https://doi.org/10.1016/j.scitotenv.2017.11.314

Publisher's Note Springer Nature remains neutral with regard to jurisdictional claims in published maps and institutional affiliations. 